TAPROBANICA, ISSN 1800-427X. June, 2014. Vol. 06, No. 01: pp. 46.

(C) Research Center for Climate Change, University of Indonesia, Depok, Indonesia \& Taprobanica Private Limited, Homagama, Sri Lanka http://www.sljol.info/index.php/tapro

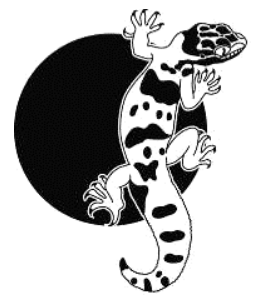

\section{Tachaea spongillicola (Cymothoida: Corallanidae) from West Bengal, India}

The isopod Tachaea spongillicola (Corallanidae) was described by Stebbing (1907) from the freshwater sponge Eunapius carteri (formerly Spongilla carteri) at the Indian Museum Tank, Kolkata, India. Since then, this species did not appear in literature for nearly hundred years. In 2003, Mariappan et al. reported this isopod from three locations along the course of the Cauvery River near Tiruchirapalli, India. They found this species to occur on three species of prawns (Table 1). However, during a recent survey at Burdwan (on 18 December 2012), the first author collected six specimens of this species (Registration Number ZSI C 6007/2) on the prawn Macrobrachium lamarrei from Damodar River at Kathgolaghat near Polempur ( 2 km
SE of Burdwan Town). The size of the isopod specimens varied between 7.6-8.0mm and 2.6$3.5 \mathrm{~mm}$. The specimens (Figs. 1) were found to fully match with the description of Stebbing (1907). Thus this endemic species is here recorded after 106 years from West Bengal.
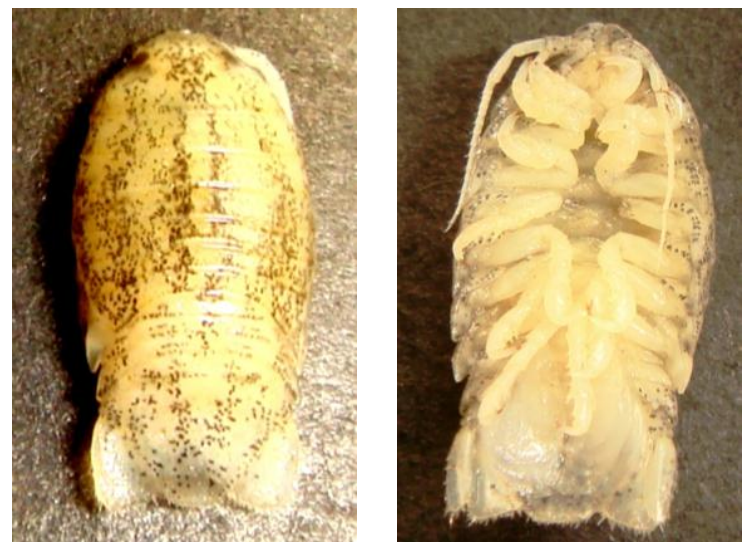

Figure 1: Tachaea spongillicola, dorsal view (left) and ventral view (right).

Table 1: Host species of Tachaea spongillicola and their distribution

\begin{tabular}{lccll}
\hline \multicolumn{1}{c}{ Species } & Group & Family & Locality and habitat & \multirow{2}{*}{ Reference } \\
\cline { 1 - 3 } $\begin{array}{l}\text { Eunapius carteri (Bowerbank, } \\
\text { 1863) }\end{array}$ & Porifera & Spongillidae & $\begin{array}{l}\text { Indian Museum Tank } \\
\text { Kolkata, India }\end{array}$ & Stebbing, 1907 \\
$\begin{array}{l}\text { Macrobrachium lamarrei } \\
\text { (Edwards, 1837) }\end{array}$ & Crustacea & Palaemonidae & $\begin{array}{l}\text { Cauvery River } \\
\text { South India }\end{array}$ & $\begin{array}{l}\text { Mariappan } \text { et al., } \\
\text { Macrobrachium lamarrei }\end{array}$ \\
$\begin{array}{l}\text { lamarrei (Edwards, 1837) } \\
\begin{array}{l}\text { Macrobrachium malcomsonii } \\
\text { (Edwards, 1844) }\end{array}\end{array}$ & Crustacea & Palaemonidae & $\begin{array}{l}\text { Damodar River } \\
\text { West Bengal, India }\end{array}$ & Present report \\
$\begin{array}{l}\text { Macrobrachium nobilii } \\
\text { (Henderson \& Matthai, 1910) }\end{array}$ & Crustacea & Palaemonidae & $\begin{array}{l}\text { Cauvery River } \\
\text { South India }\end{array}$ & $\begin{array}{l}\text { Mariappan } \text { et al., } \\
\text { 2003 }\end{array}$ \\
\hline
\end{tabular}

\section{Acknowledgement}

We thank to the Director (ZSI) for the facilities.

\section{Literature cited}

Mariappan, P., C. Balasundaram, and J-P. Trilles, 2003. The infection of isopod Tachaea spongillicola on freshwater prawns Macrobrachium spp. in southern India. Diseases of Aquatic Organisms, 55: 259-260.

Stebbing, T. R. R., 1907. A freshwater isopod from Calcutta. Journal of the Linnean Society (Zoology), London, 30: 39-41.
Submitted: 30 June 2013, Accepted: 17 Jan. 2014 Section Editor: Wolfgang Wägele

M. K. Dev Roy \& Santanu Mitra

Crustacea Section, Zoological Survey of India, 27, Jawaharlal Nehru Road, Kolkata 700016, India E-mail: malay_7@rediffmail.com 